\title{
In vitro growth inhibitory activity of Medicines for Malaria Venture pathogen box compounds against Leishmania aethiopica
}

Markos Tadele ${ }^{1 * \dagger}$, Solomon M. Abay ${ }^{2 \dagger}$, Peter Asaga ${ }^{3}$, Eyasu Makonnen ${ }^{2,4}$ and Asrat Hailu 4,5

\begin{abstract}
Introduction: Leishmania aethiopica (L. aethiopica) is responsible for different forms of cutaneous leishmaniasis (CL) in Ethiopia. Treatment heavily depends on limited drugs, together with drawbacks like toxicity and microbial resistance. The current research aimed to investigate in vitro growth inhibitory activity of Medicines for Malaria Ventures - Pathogen Box (MMV - PB) compounds against L. aethiopica clinical isolate.

Methodology: Four hundred MMV - PB compounds were screened against L. aethiopica using resazurin based colourimetric assay. Compounds with $>70 \%$ inhibition were further tested using macrophage based intracellular amastigote assay. Cytotoxic and hemolytic activity of candidate hits were assessed on THP1- cells and sheep red blood cells (RBCs), respectively. In vitro drug interaction study was also conducted for the most potent hit using the combination index method.

Results: At the test concentration of $1 \mu \mathrm{M}$, twenty-three compounds showed $>50 \%$ inhibition of promastigotes parasite growth, of which 11 compounds showed $>70 \%$ inhibition. The 50\% growth inhibition $\left(I_{50}\right)$ of the 11 compounds was ranged from 0.024 to $0.483 \mu \mathrm{M}$ in anti-promastigote assay and from 0.064 to $0.899 \mu \mathrm{M}$ in intracellular amastigote assay. Candidate compounds demonstrated good safety on sheep RBCs and THP-1 cell lines. MMV688415 demonstrated a slight hemolytic activity on sheep RBC (5.3\% at $25 \mu \mathrm{M})$ and THP-1 cell line $\left(C_{20}=25 \mu \mathrm{M}\right)$ while MMV690102 inhibited half of THP-1 cells at $36.5 \mu \mathrm{M}$ (selectivity index =478). No synergistic activity was observed from the combinations of MMV690102 and amphotericin B (Cl > 1), and MMV690102 and Pentamidine $(\mathrm{Cl}>1)$ at lower and higher combination points.

Conclusion: The present study identified a panel of compounds that can be used as a novel starting point for lead optimization. MMV690102 appears to be the most potent inhibitor against L. aethiopica promastigotes and amastigotes. Future works should investigate the antileishmanial mechanism of action and in vivo antileishmanial activities of identified hits.
\end{abstract}

Keywords: Leishmania aethiopica, Cutaneous leishmaniasis, Pathogen box

\footnotetext{
* Correspondence: markotad@gmail.com

${ }^{\dagger}$ Markos Tadele and Solomon M. Abay contributed equally to this work.

${ }^{1}$ Animal Health Research Program, Ethiopian Institute of Agricultural Research, Holetta, Ethiopia

Full list of author information is available at the end of the article
} 


\section{Introduction}

Leishmaniasis is a parasitic disease caused by an obligate intracellular protozoan of the genus Leishmania. It is clinically manifested by localized cutaneous leishmaniasis (LCL), diffuse cutaneous leishmaniasis (DCL), mucocutaneous leishmaniasis (MCL) and visceral leishmaniasis (VL) [1, 2]. While VL is typically caused by Leishmania donovani and L. infantum [3], CL is caused by a broad range of parasites. In the New World, CL is mainly caused by $L$. mexicana, L. venezuelensis, L. amazonensis, L. braziliensis, L. panamensis, L. guyanensis and L. peruviana; whereas in the Old World, it is usually caused by L. major, L. tropica, and L. aethiopica [4].

Though there are no definite epidemiological data showing the annual burden of CL in Ethiopia, it is estimated to be around $20-50,000$ cases/year $[5,6]$. In recent times, epidemics of CL and VL were observed in Amhara, Southern Peoples Nations and Nationalities Peoples Regional State and Tigray regions. The number of new cases for CL in these areas was estimated to be 10-50 per 10,000 people [7].

Ethiopian CL is almost always caused by $L$. aethiopica and rarely by L. tropica and L. major. Leishmania aethiopica is rarely encountered outside endemic area, it is predominantly restricted to Ethiopia, Kenya and Uganda [8] as well as Eritrea [9]. This parasite produces several interesting and peculiar clinical presentations. LCL is the most common form and most at times, it is self-healed while the DCL, and MCL forms of the disease have no tendency of self-cure [6] and requires systemic antileishmanial treatments. The disease is transmitted mainly by two species of phlebotomine (Phlebotomus pedifer and P. longipes) sand flies although L. aethiopica and L. tropica were recovered from $P$. sergenti and $P$. saevus, respectively [10].

Treatment for LCL is only recommended when lesions are mucosal, diffused, and complicated and if patients are immunocompromised. Current treatment trends are based on chemotherapy with systemic use of antileishmanial drugs like sodium stibogluconate, pentamidine, amphotericin B, paromomycin and miltefosine $[6,11]$. Physical therapies with liquid nitrogen (Cryotherapy) [12], heat therapy for treating lesions at $50{ }^{\circ} \mathrm{C}$ for $30 \mathrm{~s}$ up to three times are also practised [1].

Existing drugs show variable treatment responses in different parts of the country. Teklemariam et al. (1994) [13], Fikre et al. (2017) [14] and Zanger et al. (2011) [9] reported mixed therapeutic responses in DCL, MCL and LCL patients treated with common antileishmanial drugs. These reports noted very poor responses and the need for extended (up to 3.5 months) treatment duration for DCL and MCL. There is therefore the need for alternative therapeutics that can be used in combination with currently used antileishmanial drugs for the treatment of Ethiopian CL.
The PB contains 400 pure compounds active against various neglected tropical diseases. It has been previously screened for Trypanosoma brucei [15], Giardia lamblia [16] Cryptosporidium parvum and Plasmodium falciparum [17], Toxoplasma gondii [18], and recently against $L$. donovani [19] to uncover new starting points for antiprotozoal drug discovery. In this study, we screened the MMV PB to expand the pool of antileishmanial drugs active against clinical $L$. aethiopica promastigote and intracellular amastigote in vitro. This report is an independent screening of the PB against L. aethiopica.

\section{Materials and methods \\ Preparation of test and reference compounds}

The PB, composed of 400 compounds, was supplied in sealed plates containing a frozen $10 \mu \mathrm{L}$ of $10 \mathrm{mM}$ dimethyl sulfoxide (DMSO), solutions in 96-well plates. The original master plates were copied into 10 plates containing $10 \mu \mathrm{L}$ solutions at $1 \mathrm{mM}$ concentration and stored at $20^{\circ} \mathrm{C}$ till used. Amphotericin B, pentamidine isothionate, miltefosine (all from Sigma-Aldrich Che. Co., St. Louis, USA) were used as reference drugs (positive control). All compounds including the standard reference drugs were diluted with DMSO (Sigma Aldrich, Co., USA), intermediate and final dilutions were made by M199, RPMI and MEM complete media according to the assay type.

\section{Test strain, cell line, laboratory animals}

Leishmania aethiopica isolate $(579 / 17)$ was obtained from Leishmaniasis Research and Diagnostic Laboratory (LRDL), Addis Ababa University. The parasite was isolated from 50-year-old female patient residing in Ambo, Western Shoa zone, Oromia region, Ethiopia in 2017. The patient had no history of CL infection and was not treated with any kind of antileishmanial drugs before the diagnosis. The isolate was previously characterized according to the method described by [20]. Both the reference strains and the isolate were treated with standard antileishmanial drugs to see any drug susceptibility differences between them. THP-1 cell lines were obtained from Armauer Hansen Research Institute (AHRI), Addis Ababa. Swiss albino mice were obtained from college of health sciences, Addis Ababa University animal house. All procedures and techniques used in this study were in accordance with the national institute of health guidelines for the care and use of laboratory animals (Institute for Laboratory Animal Research, 2011) and following the ARRIVE Guidelines Checklist.

\section{Culture conditions}

\section{Leishmania parasite isolation and culture}

promastigotes were isolated using NNN media. Logarithmic stage $L$. aethiopica promastigotes were transferred to tissue culture flasks containing medium 199 
(M199) supplemented with $15 \%$ heat inactivated new born calf serum (HINBCS), $25 \mathrm{mM}$ 4-(2-hydroxyethyl)1-piperazineethanesulfonic acid (HEPES), $2 \mathrm{mM} \mathrm{L-glu-}$ tamine, $100 \mathrm{IU} / \mathrm{mL}$ penicillin and $100 \mu \mathrm{g} / \mathrm{mL}$ streptomycin solution (all from Sigma-Aldrich, Co., St. Louis, USA) and incubated at $22^{\circ} \mathrm{C}$ in Plate Shaker Incubator (Gerhardt).

\section{THP-1 cell line cultures}

THP-1 cells were cultured in RPMI 1640 Medium (Sigma-Aldrich, Co., St. Louis, USA) supplemented with $10 \% \mathrm{HINBCS}, 100 \mathrm{IU} / \mathrm{mL}$ penicillin, $100 \mu \mathrm{g} / \mathrm{mL}$ streptomycin at $37^{\circ} \mathrm{C}$ in $5 \% \quad \mathrm{CO}_{2}$ humidified incubator (Thermo Electron).

\section{Intra-peritoneal macrophage collection and culture}

Macrophages were collected from Swiss albino mice as described briefly in our previous work [19]. Young mice (68 weeks old) were injected into the peritoneal cavity with $2 \%$ freshly prepared starch (Sigma-Aldrich, Co., St. Louis, USA) and $10 \mathrm{~mL}$ of sterile ice-cold phosphate-buffered saline (PBS) (Sigma, Co., St. Louis, USA) supplemented with $3 \%$ HINBCS after 2 days, and 6-8 $\mathrm{mL}$ exudates were recovered. The Contents were centrifuged at $450 \mathrm{~g}$ for $10 \mathrm{~min}$ and macrophages were resuspended in essential medium (MEM) (Sigma-Aldrich, Co., St. Louis, USA) containing 10\% HINBCS, $25 \mathrm{mM}$ HEPES, $2 \mathrm{mM} \mathrm{L}$-glutamine and 100 $\mathrm{IU} / \mathrm{mL}$ penicillin and $100 \mu \mathrm{g} / \mathrm{mL}$ streptomycin.

\section{Biological assay}

\section{Primary antipromastigote assay}

Test compounds were diluted in 96-well microculture plate containing $100 \mu \mathrm{L}$ complete M199 medium. Parasite suspension $\left(1 \times 10^{6}\right.$ promastigotes $\left./ \mathrm{mL}\right)$ in $100 \mu \mathrm{L}$ media volume was then added to each well to achieve a final concentration of $1 \mu \mathrm{M}$. Plates were incubated for $72 \mathrm{~h}$ at $22^{\circ} \mathrm{C}$ in the Plate Shaker Incubator and cultured with blank wells, as well as positive (amphotericin B, miltefosine, pentamidine) and negative (DMSO at $<1 \% \mathrm{v} / \mathrm{v}$ concentration) controls.

The $\mathrm{IC}_{50}$ of test compounds against promastigote stages were performed in triplicates in a twofold dosetitration range $(0.03$ to $1 \mu \mathrm{M})$. The Parasite density was kept constant at $1 \times 10^{5}$ per well. After $68 \mathrm{~h}$ of incubation, $10 \mu \mathrm{L}$ of fluorochrome resazurin solution (SigmaAldrich, Co., St. Louis, USA) was added and the reduced resazurin was measured after an incubation time of $72 \mathrm{~h}$ at $530 \mathrm{~nm}$ excitation wavelength and $590 \mathrm{~nm}$ emission wavelength. The percentage of inhibition (\%) was calculated for each concentration using the following formula: Inhibition $(\%)=100-\frac{\text { (Fluorescence in duplicate drug wells - Fluorescence in blank wells) }}{\text { (Fluorescence }} * 100$

\section{Haemolysis test}

Serially titrated $(1.56-25 \mu \mathrm{M})$ test compounds were mixed with $2 \%$ blood suspension in Eppendorf tubes and incubated at $37^{\circ} \mathrm{C}$ for two hours with Triton X-114 $(5 \mu \mathrm{L} / \mathrm{mL})$ (Sigma-Aldrich, Co., St. Louis, USA) and 2.5\% DMSO as positive and negative controls. The mixture was then centrifuged at $1000 \mathrm{~g}$ for $10 \mathrm{~min} .75 \mu \mathrm{L}$ of the resulting supernatant were transferred to 96-well plates and the absorbance readings obtained at $540 \mathrm{~nm}$ using Victor3 Multilabel Counter (PerkinElmer, Waltham, USA).

\section{THP-1 cell cytotoxicity assay}

Approximately $2 \times 10^{5}$ THP-1 cell suspension were added to 96-well microplate containing serially diluted $50 \mu \mathrm{L}$ test compounds. Microplates were then incubated for $68 \mathrm{~h}$ at $37^{\circ} \mathrm{C}$ in a $5 \% \mathrm{CO}_{2}$ air mixture. Cell viability was determined with the resazurin- based fluorescence assay measured after a total incubation time of $72 \mathrm{~h}$. The estimated median cell cytotoxicity $\left(\mathrm{CC}_{50}\right)$ was calculated for each concentration using the formula:

Cell viability $(\%)=\frac{\text { (Fluorescence in duplicate drug wells }- \text { Fluorescence blank wells })}{\text { (Fluorescence in control wells-Fluorescence blank wells })} * 100$

\section{Selectivity index (SI)}

The selectivity index of compounds was calculated from the ratio of the $\mathrm{CC}_{50}$ value determined in THP1 cells to the $\mathrm{IC}_{50}$ value determined from the dose-response curves in promastigote and amastigote assay using the following formula.

$$
\text { Selectivity index }(\mathrm{SI})=\frac{\mathrm{CC}_{50} \mathrm{THP} 1 \text { cells }}{\mathrm{IC}_{50} \text { promastigotes or amstigotes }}
$$

\section{Physicochemical properties}

Physicochemical properties of the compounds were obtained from National Centre for Biotechnology Information (NCBI) (www.ncbi.nlm.nih.gov). The obtained physicochemical data was then checked for compliance with Lipinski's rule of absorption and permeation [21].

\section{Intracellular amastigote assay}

Intracellular amastigote assay was conducted according to the method described elsewhere $[19,22]$ with modifications. Approximately $3 \times 10^{5}$ peritoneal macrophages were seeded in 24-well plates and allowed to adhere for $12 \mathrm{~h}$ at $33{ }^{\circ} \mathrm{C}$ in $5 \% \mathrm{CO}_{2}$. Adherent cells were infected with late-stage $L$. aethiopica promastigotes (1:10 ratio) after washing out non-adherent cells twice. Only when $>70 \%$ of the macrophages present in the wells were infected was the infection deemed sufficient. The medium was then replaced with a fresh complete medium with or without test compounds and incubated for $72 \mathrm{~h}$ at $33{ }^{\circ} \mathrm{C}$ and $5 \% \mathrm{CO}_{2}$. After $72 \mathrm{~h}$ of incubation, slides were 
washed with prewarmed PBS, fixed with methanol, and stained with Giemsa (10\%) for $15 \mathrm{~min}$ and observed under 100x oil immersion objective microscope [Olympus]. Amphotericin B and pentamidine were used as reference drugs against test samples.

\section{Determination of $I C_{50}$ against intracellular amastigotes}

The $\mathrm{IC}_{50}$ was determined by counting amastigotes in (50) macrophages in duplicate cultures. In all assays except for haemolytic and THP- 1, test compounds were diluted in a two-fold dose-titration range (0.03 to $1 \mu \mathrm{M})$ in triplicate. Parasite burden was calculated using the infection index as shown below.

$$
\begin{aligned}
\text { Infection index } & =\frac{\text { Number of infected macrophages }}{\text { Total macrophage counted }} \\
& \times \frac{\text { Total number of amastigotes in infected macrophages }}{\text { Total infected macrophages counted }}
\end{aligned}
$$

The $\mathrm{IC}_{50}$ of each test compound was defined as the inhibitory concentration of test compounds that reduces the number of amastigotes per infected macrophages by $50 \%$.

\section{Evaluation of the synergistic activity of molecules}

In vitro drug interactions were assessed using the combination index method as described by Chou and Martin [23]. The dose-response relationship of each drug alone and in combination was assessed separately as illustrated in Table 1.

\section{Statistical analysis}

Percentage inhibition for each test and reference compounds were expressed as mean values $\pm 95 \%$ confidence interval $(\mathrm{CI})$. The $\mathrm{IC}_{50}$ values were determined by GraphPad Prism version 8.4 (GraphPad software, inc. 2020) using non-linear regression model: $Y=100 /(1+$ $10^{\wedge}\left(\left(\operatorname{LogIC} C_{50}-\mathrm{X}\right)^{*}\right.$ Hillslope $\left.\left.)\right)\right)$. Where, $\mathrm{X}=\log$ of concentration, $\mathrm{Y}=$ Normalized response $(0-100 \%), \log \mathrm{IC}_{50}=$ same $\log$ units as $\mathrm{X}$ HillSlope $=$ Slope factor or Hill slope. Pooled data were expressed as means $\pm 95 \%$ CI of two independent experiments, with each test concentration in triplicates. Drug combination effects of each selected compound with their references were assessed using isobologram and the analysis was made using Compusyn (CompuSyn 1.0, ComboSyn, Inc., 2005).

\section{Results}

\section{Primary screening and dose titration assay}

The preliminary screening uses $L$. aethiopica promastigotes. All 400 compounds were screened at $1 \mu \mathrm{M}$ (Supportive file Fig. 1 and Supportive file Table 1). From which, 23 compounds had $>50 \%$ inhibitory effect in the initial screening process. Eleven of the 23 compounds had an inhibitory activity of $>70 \%$ as shown in the radar map (Fig. 1). The radar was developed using the average percentage of each inhibitor compound obtained from two independent experiments conducted in triplicates.

Active compounds which demonstrated $>70 \%$ promastigote inhibitory activity were selected for further analysis. The $\mathrm{IC}_{50}$ values for all tested compounds were below $0.483 \mu \mathrm{M}$; of these, MMV024406, MMV688415 and MMV690102 demonstrated IC50 of $0.024 \mu \mathrm{M}$, $0.145 \mu \mathrm{M}$ and $0.158 \mu \mathrm{M}$, respectively on the primary dose titration assay performed on promastigotes (Table 2).

The molecular structure of the most potent (>70\% inhibition) Pathogen Box compounds against L. aethiopica promastigotes are indicated in Fig. 2.

\section{Cytotoxicity study}

The study shows MMV688415 to have hemolytic activity on sheep RBC (5.3\% hemolytic activity at $25 \mu \mathrm{M})$ and THP-1 cell line $\left(C_{20}=25 \mu \mathrm{M}\right)$. MMV690102 it also demonstrated an inhibitory activity on THP-1 cell lines with an extrapolated $\mathrm{IC}_{50}$ value of $36.55 \mu \mathrm{M}(95 \% \mathrm{CI}$ : 29.86-45.36). The calculated selectivity index (SI) for MMV690102 was 478.4.

\section{Physicochemical properties}

MMV687812 was found to be higher than the $500 \mathrm{~g} / \mathrm{mol}$ molecular weight and the 10-hydrogen bond receiver count. This clearly violates Lipinski's rule of permeation and absorption. Hence, it was discarded from further screening (Table 3).

\section{Activity of selected compounds against Leishmania aethiopica amastigotes}

Ten compounds were screened at $1 \mu \mathrm{M}$ for their activity against intracellular amastigotes. Out of these, only six compounds showed $>50 \%$ inhibition at $1 \mu \mathrm{M}$. The percentage of inhibition observed at $1 \mu \mathrm{M}$ was MMV690102 (90.7 \pm 5.3$), \quad$ MMV085071 (80.5 \pm 4.2$), \quad$ MMV688415

\begin{tabular}{|c|c|c|c|c|c|}
\hline Drug 1 & $4\left(I C_{50}\right)=A$ & $2\left(I_{50}\right)=C$ & $\left(I C_{50}\right)=E$ & $\left(I C_{50}\right) / 2=G$ & $\left(I C_{50}\right) / 4=I$ \\
\hline Drug 2 & $4\left(I C_{50}\right)=B$ & $2\left(I C_{50}\right)=D$ & $\left(I C_{50}\right)=F$ & $\left(I C_{50}\right) / 2=H$ & $\left(I C_{50}\right) / 4=J$ \\
\hline Combination & $A+B$ & $C+D$ & $E+F$ & $\mathrm{G}+\mathrm{H}$ & $I+J$ \\
\hline
\end{tabular}
(68.6 \pm 6.6$), \quad$ MMV022478 (72.4 \pm 5.6$), \quad$ MMV024829

Table 1 Layout of a combination experiment for synergistic effect of two drugs

The combination index $(\mathrm{Cl})$ values were estimated to be $\mathrm{Cl}<1,=1$, and $>1$ which indicate synergism, additive, and antagonism, respectively 


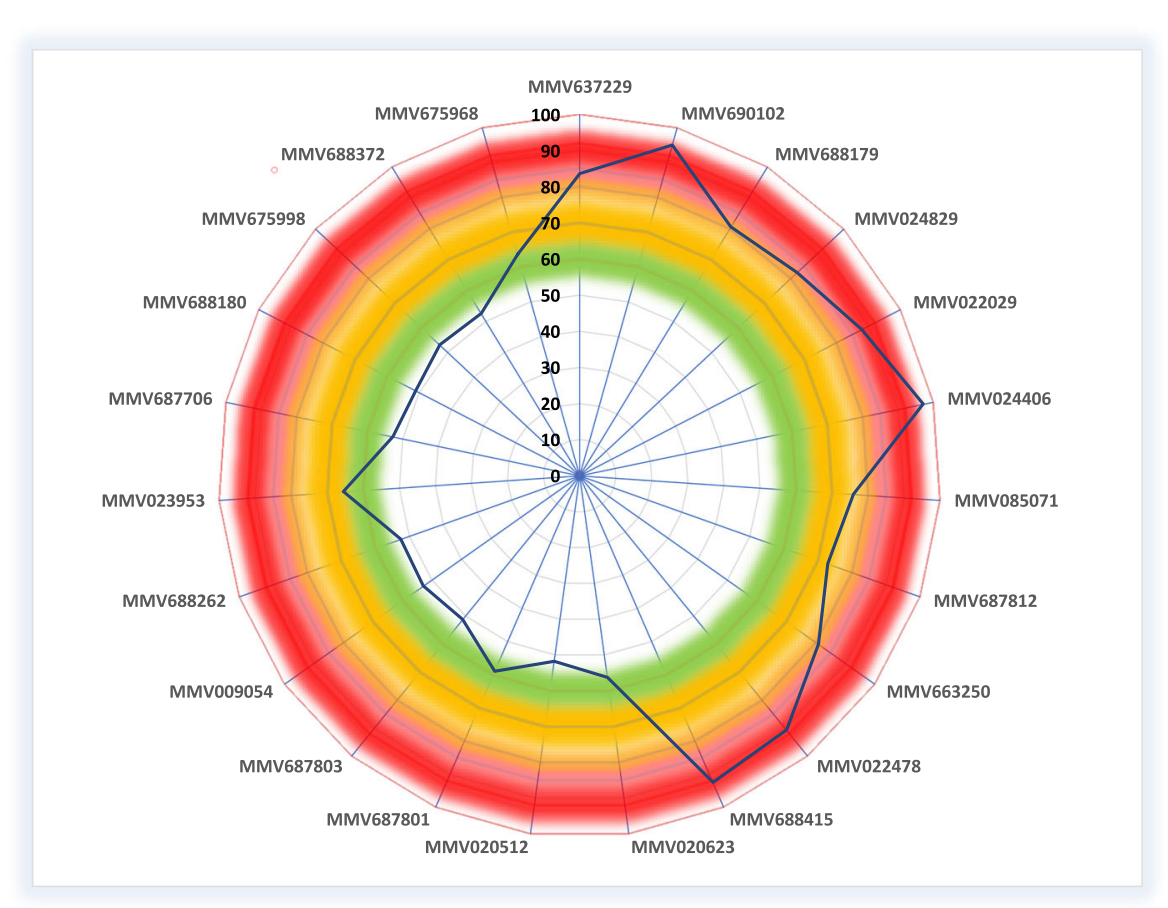

Fig. 1 Radar graph illustrating the percent inhibition of PB compounds against $L$ aethiopica promastigotes at $1 \mu \mathrm{M}$. The red colour corresponds to the highest inhibitions (more than 85\%). The orange zone represents $70-85 \%$ inhibition, while the green zone corresponds to $50-70 \%$ inhibition. The experiment was conducted using amphotericin B and Pentamidine as standard

$(69.6 \pm 4.1)$ and MMV024406 (55.6 \pm 5.5$)$. The remaining 4 compounds could not produce $>50 \%$ intracellular amastigote reduction. MMV690102 was found to be a very potent inhibitor of $L$. aethiopica amastigotes (Fig. 3). MMV biological data also showed $\mathrm{IC}_{50}$ value $3 \mathrm{nM}$ on $L$. infantum, 20-fold lower.

\section{Synergistic effect of the identified hits with reference drugs}

Based on the performance of the intracellular amastigotes assay, MMV690102 was evaluated for its synergistic effect with pentamidine and amphotericin B. The combination index values for the two combination MMV690102-pentamidine $\quad\left(\mathrm{ED}_{50}=2.67, \quad \mathrm{ED}_{75}=2.54\right.$, $\left.\mathrm{ED}_{90}=2.42, \quad \mathrm{ED}_{95}=2.34\right) \quad$ and $\mathrm{MMV690102-}$ amphotericin $\mathrm{B}\left(\mathrm{ED}_{50}=1.88, \mathrm{ED}_{75}=2.18, \mathrm{ED}_{90}=2.56\right.$, $\left.\mathrm{ED}_{95}=2.88\right)$ were $>2$, indicating the combination have no synergistic effect and are less relevant to combination therapy (supportive file Fig. 2).

\section{Discussion}

The sole purpose of the primary screening was to generate a complete hit map for all 400 compounds at $1 \mu \mathrm{M}$ (Supplemented Fig. 1). The map was developed using the average percentage of inhibition of each compound obtained from two independent experiments in triplicate. The list of compounds that showed $>50 \%$ inhibitive activity is presented in the radar graph (Fig. 1). Of which, 11 compounds with $>70 \%$ inhibition were taken for further investigation in a dose titration assay against $L$. aethiopica promastigotes.

MMV690102 was found to be a very potent inhibitor of both forms of the parasite. This finding is consistent with the reports of Berry et al. [25] and Duffy et al. [24] which used L. Mexicana and L. donovani strains, respectively. We previously reported MMV690102 as one of the potent growth inhibitors of $L$. donovani promastigotes and amastigotes [19]. This indicates the potentials of this compound for the treatment of infections caused by more than one Leishmania species types. MMV085071, MMV022478 and MMV688415 also exhibited good activities on $L$. aethiopica intracellular amastigotes (Fig. 2).

The present study showed that the calculated SI of MMV690102 based on the cytotoxicity activity against THP-1 cell lines was greater than 100 (SI = 478.4). MMV reported $\mathrm{IC}_{50}$ value of $5.4 \mu \mathrm{M}$ and $4 \mu \mathrm{M}$ against MRC-5 and PMM cells. Other useful information such as DMPK are also available from the MMV PB website www.mmv.org/mmv-open/pathogen-box/aboutpathogen-box\#composition. The inhibition observed on 
Table 2 Activity of Selected Compounds against Leishmania aethiopica promastigotes

\begin{tabular}{|c|c|c|c|c|c|c|}
\hline \multirow{2}{*}{$\begin{array}{l}\text { Plate-well } \\
\text { location }\end{array}$} & \multirow[t]{2}{*}{ MMV ID } & \multirow[t]{2}{*}{$\mathrm{IC}_{50}(95 \% \mathrm{CI})$} & \multicolumn{2}{|c|}{ Cytotoxicity, $\mathrm{CC}_{50}(\mathrm{SI}), \mu \mathrm{M}$} & \multirow[t]{2}{*}{ Mode of action } & \multirow[t]{2}{*}{ Previous activity report } \\
\hline & & & Sheep RBC & THP-1 & & \\
\hline B-F5 & MMV637229 & $0.483(0.340-0.740)$ & $>25$ (ND) & $>25$ (ND) & Antihistamine & T. cruzi, L. donovani $[19,24]$ \\
\hline C-E8 & MMV690102 & $0.158(0.086-0.213)$ & $>25$ (ND) & $36(478) *$ & DHFR inhibitors & L.donovani, L.mexicana $[24,25]$ \\
\hline $\mathrm{C}-\mathrm{F} 3$ & MMV688179 & $0.356(0.180-0.440)$ & $>25$ (ND) & $>25$ (ND) & DNA interfere with DNA multiplication & T. brucei and L. donovani [24] \\
\hline D-B5 & MMV024829 & $0.356(0.174-0.352)$ & $>25$ (ND) & $>25$ (ND) & - & - \\
\hline D-B7 & MMV022029 & $0.305(0.241-0.364)$ & $>25$ (ND) & $>25$ (ND) & - & T. brucei [24] \\
\hline D-D11 & MMV024406 & $0.024(0.016-0.031)$ & $>25$ (ND) & $>25$ (ND) & - & C. albicans [26] \\
\hline D-E4 & MMV085071 & $0.283(0.110-0.471)$ & $>25$ (ND) & $>25$ (ND) & $\begin{array}{l}\text { DV disruption, mitochondrial } \\
\text { degradation \& DNA fragmentation }\end{array}$ & P. falciparum [27] \\
\hline D-F11 & MMV687812 & $0.390(0.285-0.502)$ & $>25$ (ND) & $>25$ (ND) & DV-disrupting/ DNA degradation & P. falciparum [27] \\
\hline D-G6 & MMV663250 & $0.326(0.190-0.530)$ & $>25(\mathbf{N D})$ & $>25$ (ND) & - & - \\
\hline $\mathrm{D}-\mathrm{H} 3$ & MMV022478 & $0.448(0.138-0.580)$ & $>25$ (ND) & $>25$ (ND) & $\begin{array}{l}\text { NADPH oxidase inhibitors via inhibition } \\
\text { of protein kinase C [28] }\end{array}$ & L. donovani, T. gondi $[18,19,24]$ \\
\hline E-G11 & MMV688415 & $0.145(0.102-0.180)$ & $>25$ (ND) & $>25$ (ND) & - & T. cruzi [24] \\
\hline \multicolumn{2}{|c|}{ Amphotericin B } & $0.106(0.06-0.140)$ & & & & \\
\hline \multicolumn{2}{|l|}{ Pentamidine } & $1.31(0.728-1.92)$ & & & & \\
\hline
\end{tabular}

Description: $95 \%$ Cl 95\% confidence interval, $I C_{50}$ Median inhibitory concentration, $D V$ digestive vacuole, $S /$ selectivity index, $N D$ not determined, ${ }^{*}$ extrapolated result. The $I_{50}$ value indicated was the average of two independent experiments conducted in triplicate

these two mammalian cells is lower compared to the effect observed on THP-1 and RBC in this study. It is therefore very imperative to conduct additional cytotoxicity studies on other mammalian cells. Compounds under the same class are less selective between the host cells and other DHFR expressing eukaryotes.

MMV688179 is analogue of furamidine, which is an amphipathic diamine antiprotozoal drug. Though the mechanism of action is not clearly indicated, the analogues are known to bind with DNA at the AT sites and form DNA-drug complexes and interfere with replication [40, 41]. MMV022478 is a member of the pyrazolo [1,5-a] pyrimidine class which has been identified as an inhibitor of NADPH oxidase through inhibition of protein kinase C $[28,42]$. The activity of MMV688415 and MMV022478 against T. cruzi [24] and Toxoplasma gondii and T. cruzi [24, 43], had previously been reported, without compelling evidence on their biological target. MMV637229 had been reported to inhibit histamine receptor [44]. MMV687812 was identified as a potent digestive vacuole (DV) disruptive antimalarial agent, with the most pronounced DV-disrupting DNA degradation capacities [27]. The novelty of this screening is the first of its kind on L. aethiopica species, as a result, there was no published work to compare our findings.

MMV022029 and MMV024406 demonstrated high inhibition properties at $1 \mu \mathrm{M}$ in the promastigote growth inhibition assay. However, their activities against the intracellular amastigotes were low. Reduction of activity in the intracellular assay is expected as these compounds traverse through the membranes to reach their site of action $[45,46]$. A significant reduction of activity like this one might suggest poor membrane permeability and stability in the acidic and hydrolytic environment of parasitophorous vacuoles [47] or maybe the biological target variation between promastigotes and amastigotes forms.

Poor membrane permeability is directly associated with XLogP3-AA values. The physiochemical data gathered from NCBI (Table 3) showed MMV022029 and MMV024406 having XLogP3-AA value of 3.9 and 4, respectively, which is close to the cut-off point for computational $\log \mathrm{P}(\mathrm{C} \log \mathrm{P})$ for acceptable absorption or permeation. This might play a role in poor intracellular inhibitory activity as membrane permeability is inversely correlated with XLogP3-AA value. In addition to drug permeation property, inherent differences in transcriptomes and proteosomes of amastigotes and promastigotes may cause difference in susceptibility [48]. The cell growth and metabolism difference between promastigotes and amastigotes can also be a factor. The former unlike the latter is known for its high and rapid proliferation [48] which makes it susceptible for growth-limiting agents.

\section{Conclusion}

In this study, five compounds were identified as confirmed hits agents for L. aethiopica. Further In vivo 
<smiles>CN(C)C(C)(C)C</smiles>

MMV024829<smiles>Cc1cccc(C(=O)Nc2ccnc(N(C)C3CCN(CC(C)C)CC3)c2)c1</smiles>

\section{MMV688179}<smiles>N=C(N)Nc1ccc(-c2ccc(-c3ccc(NC(=N)N)cc3Cl)o2)c(Cl)c1</smiles>

MMV687812

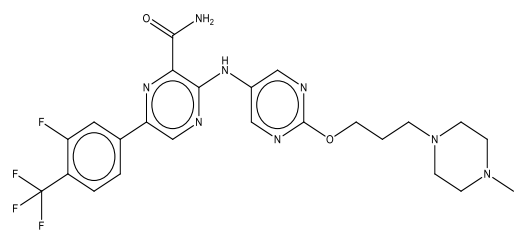

MMV085071<smiles>COc1cncc(-c2cncc(N3CCN(c4ccncc4)CC3)n2)c1</smiles>

MMV022029<smiles>CN1CCC(NCc2cccc(-c3ccc(C(=O)NCc4ccccc4)cc3)c2)CC1</smiles>

MMV690102<smiles>COc1ccc(Oc2ccc([C@H](C)N(C)c3ncc4c(N)nc(N)nc4n3)cc2)cc1</smiles>

MMV022478<smiles>O=C(Nc1ccc(N2CC[CH]CC2)cc1)c1ccc2[nH]cc(-c3cccc(O)c3)c2n1</smiles>

MMV663250<smiles>Clc1cccc(C(c2ccc(CN3CCNCC3)cc2)n2ccnc2)c1</smiles>

MMV637229

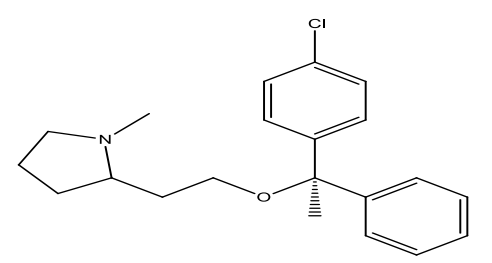

Fig. 2 Structures of pathogen box compounds with $>70 \%$ promastigote growth inhibition at $1 \mu \mathrm{M}$

Table 3 Physicochemical properties of selected compounds

\begin{tabular}{llllllll}
\hline MMV ID & R1 & R2 & R3 & R4 & R5 & R6 & Reference \\
\hline MMV688179 & 403.3 & 4 & 3 & 4 & 2.5 & 142 & {$[29]$} \\
MMV085071 & 348.4 & 0 & 7 & 4 & 1.3 & 67.3 & {$[30]$} \\
MMV688415 & 433.5 & 2 & 6 & 6 & 2.3 & 69.1 & {$[31]$} \\
MMV024406 & 428.3 & 1 & 5 & 4 & 3.9 & 61.4 & {$[32]$} \\
MMV663250 & 366.1 & 1 & 3 & 5 & 3.1 & 33.1 & {$[33]$} \\
MMV637229 & 343.9 & 0 & 2 & 6 & 5 & 12.5 & {$[34]$} \\
MMV690102 & 417.4 & 2 & 9 & 6 & 3.3 & 125 & {$[35]$} \\
MMV022478 & 432.9 & 2 & 5 & 4 & 3.2 & 74.6 & {$[36]$} \\
MMV024829 & 380.5 & 1 & 4 & 6 & 4.4 & 48.5 & {$[37]$} \\
MMV687812 & 534.5 & 2 & 13 & 9 & 2.9 & 122 & {$[38]$} \\
MMV022029 & 449.6 & 2 & 5 & 8 & 4 & 69.8 & {$[39]$}
\end{tabular}

Description: $R 1$ Molecular weight $(\mathrm{g} / \mathrm{mol}), R 2 \mathrm{H}^{+}$bond donor, $R 3 \mathrm{H}^{+}$bond receiver, $R 4$ Rotatable bonds, $R 5$ XLogP3-AA, $R 6$ Polar surface area $\left(\mathrm{A}^{2}\right)$. Lipinski's rule of five (RO5) associate compounds with more than $5 \mathrm{H}$-bond donors, $10 \mathrm{H}$-bond acceptors, molecular weight greater than 500 and computational $\log \mathrm{P}(\mathrm{C} \log \mathrm{P})$ greater than 5 (or Moriguchi $\log \mathrm{P}[\mathrm{MLog} \mathrm{P}]>4.15$ ) poor absorption and/or permeation and in vitro analytical assessments are needed to evaluate their safety, pharmacokinetic profile and antileishmanial mechanism using target-based experiments. We performed the intracellular assay based on the activity of compounds in the preliminary assay. This method might mask compounds with low inhibitory activity on promastigotes, otherwise effective against the intracellular stage. We, therefore, recommend high throughput screening of the library against the amastigote forms. Majority of the compounds identified in this study lacked relevant biological data. Therefore, their pharmacokinetics studies, as well as related activities on mammalian cells, should also be conducted.

In the intracellular assay, the performance of MMV022029 and MMV024406 were significantly reduced; structural optimization can be conducted to improve target binding affinity, physicochemical and pharmacokinetic properties, and maximize the in vitro 


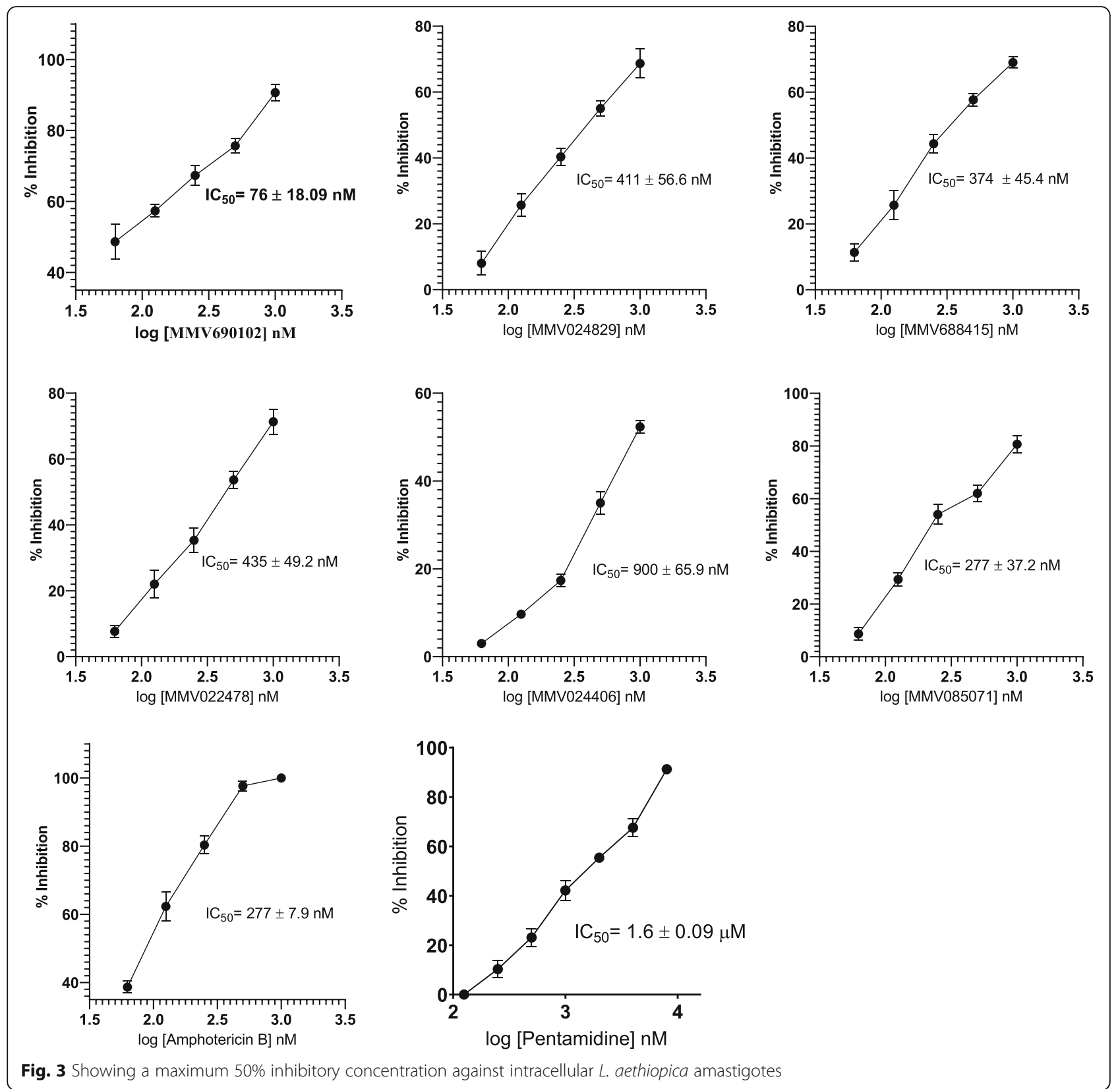

potency. Moreover, in vivo animal models can also be considered to check if there is a need for bioactivation.

\section{Supplementary Information}

The online version contains supplementary material available at https://doi. org/10.1186/s40360-021-00538-2.

Additional file 1: Supportive file Fig. 1. Heat map of percent inhibition of pathogen box compounds against Leishmania aethiopica promastigotes.

Additional file 2: Supportive file Fig. 2. Dose-effect curve and isobologram analysis for synergistic effect of MMV690102 with amphotericin $B[1: 1])$ and pentamidine combination [1:20].
Additional file 3: Supportive file Table 1. Hit map with actual Percentage of inhibition of MMV pathogen Box compounds against Leishmania aethiopica promastigotes at $1 \mu \mathrm{M}$.

\section{Acknowledgments}

We are grateful to Dr. Adane Meheret for providing the THP-1 cell lines, and the staff of Leishmania Research and Diagnostic Laboratory (LRDL) of Addis Ababa University for all their support and assistance provided throughout the study period.

\section{Authors' contributions}

Conceptualization and design the experiment: MT, SMA, PA, EM, AH; Investigation: MT, SMA, AH; Data analysis: MT, SMA; Funding acquisition and reagents contribution: SMA, $A H$. Supervision: SMA, EM, AH; Writing - original 
draft: MT; Writing - review \& amp; editing: MT, SMA, EM, AH, PA. The author(s) read and approved the final manuscript.

\section{Funding}

This work was supported by the Medicines for Malaria Venture's Exploiting the PB Challenge Grants PO 15/01083[04] (PI Abay S.). The authors acknowledge MMV for providing access to the PB.

\section{Availability of data and materials}

The datasets supporting the conclusions of this article are included within the article. Additional data will be available upon request from corresponding author

\section{Declarations}

\section{Ethics approval and consent to participate}

Ethical approval was obtained from the Departmental Research Ethics Committee, Department of Pharmacology and Clinical Pharmacy, School of Pharmacy, College of Health Sciences, Addis Ababa University (ERB/SOP/37/ 10/2018 dated Jan 01, 2018). Informed consent was obtained from the patient shortly after diagnosis which permits the use of the isolate for research purposes. Confidentiality and privacy kept by omitting the name of the patient. All procedures and techniques used in this study were per the national institute of health guidelines for the care and use of laboratory animals (Institute for Laboratory Animal Research, 2011) and following the ARRIVE Guidelines Checklist.

\section{Consent for publication}

Not applicable.

\section{Competing interests}

There are no competing interests in this work.

\section{Author details}

'Animal Health Research Program, Ethiopian Institute of Agricultura Research, Holetta, Ethiopia. ${ }^{2}$ Department of Pharmacology and Clinical Pharmacy, College of Health Sciences, Addis Ababa University, Addis Ababa, Ethiopia. ${ }^{3}$ Institute of Human Virology, University Freiburg Medical Centre, Freiburg, Germany. ${ }^{4}$ Center for Innovative Drug Development and Therapeutic Trials for Africa (CDT Africa), College of Health Sciences, Addis Ababa University, Addis Ababa, Ethiopia. ${ }^{5}$ Department of Microbiology, Immunology and Parasitology, College of Health Sciences, Addis Ababa University, Addis Ababa, Ethiopia.

Received: 28 January 2021 Accepted: 28 October 2021

Published online: 16 November 2021

\section{References}

1. Prasad N, Ghiya BC, Bumb RA, Kaushal H, Saboskar AA, Lezama-davila CM, et al. Case Report Heat, Oriental sore, and HIV. Lancet. 2011;377(9765):610. https://doi.org/10.1016/S0140-6736(10)61495-X.

2. Peters W, Evans DA, Lanham SM. Importance of parasite identification in cases of leishmaniasis. J R Soc Med. 1983;76:70540-2.

3. Aggarwal $P$, Handa $R$, Singh S, Wali JP. Kala-azar - N e w developments in diagnosis and treatment. Indian J Pediatr. 1999;66(1):63-71. https://doi.org/1 $0.1007 /$ BF02752355.

4. Reithinger R, Dujardin J, Louzir H, Pirmez C, Alexander B, Brooker S, et al. Cutaneous leishmaniasis. Lancet Infect Dis. 2007:7(9):581-91. https://doi. org/10.1016/S1473-3099(07)70209-8.

5. Alvar J, Vélez ID, Bern C, Herrero M, Desjeux P, Cano J, et al. Leishmaniasis worldwide and global estimates of its incidence. PLoS One. 2012;7(5). https://doi.org/10.1371/journal.pone.0035671.

6. van Griensven J, Gadisa E, Aseffa A, Hailu A, Beshah AM, Diro E. Treatment of cutaneous Leishmaniasis caused by Leishmania aethiopica: a systematic review. PLoS Negl Trop Dis. 2016;10(3):1-20. https://doi.org/10.1371/journal. pntd.0004495

7. WHO. Leishmaniasis. Country General Information, Ethiopia: WHO Press Rep; 2016.

8. Olobo-Okao J, Sagaki P. Leishmaniasis in Uganda: historical account and a review of the literature. Pan Afr Med J. 2014;18:1-7.
9. Zanger P, Kötter I, Raible A, Gelanew T, Schönian G, Kremsner PG. Case report: successful treatment of cutaneous leishmaniasis caused by Leishmania aethiopica with liposomal amphothericin B in an immunocompromised traveler returning from Eritrea. Am J Trop Med Hyg. 2011;84(5):692-4. https://doi.org/10.4269/ajtmh.2011.10-0712.

10. van Henten S, Adriaensen W, Fikre H, Akuffo H, Diro E, Hailu A, et al. Cutaneous Leishmaniasis due to Leishmania aethiopica. EClinicalMedicine. 2018;6:69-81. https://doi.org/10.1016/j.eclinm.2018.12.009.

11. Utaile M, Kassahun A, Abebe T, Hailu A. Experimental Parasitology Susceptibility of clinical isolates of Leishmania aethiopica to miltefosine paromomycin , amphotericin B and sodium stibogluconate using amastigote-macrophage in vitro model. Exp Parasitol. 2013;134(1):68-75. https://doi.org/10.1016/j.exppara.2013.01.022.

12. Negera E, Gadisa E, Hussein J, Engers H, Kuru T, Gedamu L, et al. Treatment response of cutaneous leishmaniasis due to Leishmania aethiopica to cryotherapy and generic sodium stibogluconate from patients in Silti, Ethiopia. Trans R Soc Trop Med Hyg. 2012;106(8):496-503. https://doi.org/1 0.1016/j.trstmh.2012.02.006

13. Teklemariam S, Hiwot AG, Frommel D, Mike TL, Ganlov G, Bryceson A. Aminosidine and its combination with sodium stibogluconate in the treatment of diffuse cutaneous leishmaniasis caused by leishmania aethiopica. Trans R Soc Trop Med Hyg. 1994;88(3):334-9. https://doi.org/10.1 016/0035-9203(94)90106-6.

14. Fikre H, Mohammed R, Atinafu S, van Griensven J, Diro E. Clinical features and treatment response of cutaneous leishmaniasis in north-West Ethiopia. Tropical Med Int Health. 2017;22(10):1293-301. https://doi.org/10.1111/ tmi.12928.

15. Veale CGL, Hoppe HC. Screening of the Pathogen Box reveals new starting points for anti-trypanosomal drug discovery. Medichemcommun. 2018;9(12): 2037-44. https://doi.org/10.1039/C8MD00319J.

16. Hennessey KM, Rogiers IC, Shih HW, Hulverson MA, Choi R, McCloskey MC, et al. Screening of the pathogen box for inhibitors with dual efficacy against Giardia lamblia and Cryptosporidium parvum. PLoS Negl Trop Dis. 2018:12(8):1-16. https://doi.org/10.1371/journal.pntd.0006673.

17. XinTong J, Rajesh Chandramohanadas KS-WT. Crossm high-content screening of the Medicines for Malaria Venture pathogen box for plasmodium falciparum digestive vacuole. Antimicrob Agents Chemother. 2018;62:1-17.

18. Spalenka J, Escotte-Binet S, Bakiri A, Hubert J, Renault J-H, Velard F, et al. Discovery of new inhibitors of toxoplasma gondii via the pathogen box. Antimicrob Agents Chemother. 2018;62(2):1-10. https://doi.org/10.1128/AA C.01640-17.

19. Tadele M, Abay SM, Makonnen E, Hailu A. Leishmania donovani growth inhibitors from pathogen box compounds of medicine for malaria venture. Drug Des Devel Ther. 2020;14:1307-17. https:/doi.org/10.2147/DDDT.S244903.

20. Gadisa E, Genetu A, Kuru T, Jirata D, Dagne K, Aseffa A, et al. Leishmania (Kinetoplastida): species typing with isoenzyme and PCR-RFLP from cutaneous leishmaniasis patients in Ethiopia. Exp Parasitol. 2007;115(4):33943. https://doi.org/10.1016/j.exppara.2006.09.014

21. Lipinski CA, Lombardo F, Dominy BW, Feeney PJ. Experimental and computational approaches to estimate solubility and permeability in drug discovery and development settings. Adv Drug Deliv Rev. 2001;46:3-26.

22. Vermeersch $M$, Inoce $R$, Tote $K$, Timmermans J, Cos $P$, Maes $L$. In vitro susceptibilities of Leishmania donovani promastigote and amastigote stages to Antileishmanial reference drugs : practical relevance of stage-specific differences. Antimicrob Agents Chemother. 2009;53(9):3855-9. https://doi. org/10.1128/AAC.00548-09

23. Chou T-C, Martin N. CompuSyn for drug combinations and for general dose-effect analysis User's guide. 2007. www.combosyn.com.

24. Duffy S, Sykes ML, Jones AJ, Shelper TB, Simpson M, Lang R, et al. Screening the medicines for malaria venture pathogen box across multiple pathogens reclassifies starting points for open-source drug discovery. Antimicrob Agents Chemother. 2017;61(9):1-22. https://doi.org/10.1128/AAC.00379-17.

25. Berry SL, Hameed H, Thomason A, Maciej-Hulme ML, Saif Abou-Akkada S, Horrocks $P$, et al. Development of NanoLuc-PEST expressing Leishmania mexicana as a new drug discovery tool for axenic- and intramacrophagebased assays. PLoS Negl Trop Dis. 2018;12(7):1-20. https://doi.org/10.1371/ journal.pntd.0006639.

26. Vila T, Lopez-Ribot JL. Screening the "Pathogen Box" for the Identification of Candida albicans Biofilm Inhibitors. Antimicrob Agents Chemother. 2016. https://doi.org/10.1128/AAC.02006-16. 
27. Tong JX, Chandramohanadas R, Tan KS-W. High-content screening of the Medicines for Malaria Venture pathogen box for plasmodium falciparum digestive vacuole. Antimicrob Agents Chemother. 2018;62(3):1-17. https:// doi.org/10.1128/AAC.02031-17.

28. Altenhofer S, Radermacher KA, Kleikers PWM, Wingler K, Schmidt HHHW. Evolution of NADPH oxidase inhibitors : selectivity and mechanisms for target engagement: Antioxidants \& Redox Signaling; 2015. p. 406-27.

29. NCBI. 2,5-Bis (2-chloro-4-guanidinophenyl) furan | C18H16Cl2N6O PubChem. 2018. https://pubchem.ncbi.nlm.nih.gov/compound/487976. Accessed 22 Sep 2018.

30. NCBI. C19H20N6O - PubChem. 2018. https://pubchem.ncbi.nlm.nih.gov/ compound/45488325. Accessed 27 Oct 2018.

31. NCBI. C26H31N3O3 - PubChem. 2018. https://pubchem.ncbi.n/m.nih.gov/ compound/122196559. Accessed 27 Oct 2018.

32. NCBI. C21H19Cl2N5O - PubChem. 2018. https://pubchem.ncbi.nlm.nih.gov/ compound/44527543. Accessed 27 Oct 2018.

33. NCBI. C21H23CIN4 - PubChem. 2018. https://pubchem.ncbi.nlm.nih.gov/ compound/129011764. Accessed 27 Oct 2018.

34. NCBI. C21H26CINO - PubChem. 2018. https://pubchem.ncbi.nlm.nih.gov/ compound/68896369. Accessed 27 Oct 2018.

35. NCBI. C22H23N7O2 - PubChem. 2018. https://pubchem.ncbi.nlm.nih.gov/ compound/122196562. Accessed 27 Oct 2018.

36. NCBI. C23H21CIN6O - PubChem. 2018. https://pubchem.ncbi.nlm.nih.gov/ compound/44524414. Accessed 27 Oct 2018.

37. NCBI. C23H32N4O - PubChem. 2018. https://pubchem.ncbi.nlm.nih.gov/ compound/44528288. Accessed 27 Oct 2018.

38. NCBI. C24H26F4N8O2 - PubChem. 2018. https://pubchem.ncbi.nlm.nih.gov/ compound/71596999. Accessed 27 Oct 2018.

39. NCBI. C26H31N3O2S - PubChem. 2018. https://pubchem.ncbi.nlm.nih.gov/ compound/44523667. Accessed 27 Oct 2018.

40. Ross BN, Myers JN, Muruato LA, Tapia D, Torres AG. Evaluating new compounds to treat Burkholderia pseudomallei infections. Front Cell Infect Microbiol. 2018:8:1-8.

41. Wang L, Bailly C, Kumar A, Ding D, Bajic M, Boykin DW, et al. Specific molecular recognition of mixed nucleic acid sequences: an aromatic dication that binds in the DNA minor groove as a dimer. Proc Natl Acad Sci U S A. 2000:97(1):12-6. https://doi.org/10.1073/pnas.97.1.12

42. Gatto GJ, Ao Z, Kearse MG, Zhou M, Morales CR, Daniels E, et al. NADPH oxidase-dependent and -independent mechanisms of reported inhibitors of reactive oxygen generation. J Enzyme Inhib Med Chem. 2013;28(1):95-104. https://doi.org/10.3109/14756366.2011.636360.

43. Baska F, Szabadkai I, Horvath Z, Marko P, Varga Z, Breza N, et al. Smallmolecule inhibitors of NADPH oxidase 4. J Med. 2010;53:6758-62.

44. Planer JD, Hulverson MA, Arif JA, Ranade RM, Don R, Buckner FS. Synergy testing of FDA-approved drugs identifies potent drug combinations against Trypanosoma cruzi. PLoS Negl Trop Dis. 2014;8(7):e2977. https://doi.org/1 0.1371/journal.pntd.0002977.

45. Kima PE. The amastigote forms of Leishmania are experts at exploiting host cell processes to establish infection and persist. Int J Parasitol. 2008;37(10): 1087-96. https://doi.org/10.1016/j.jpara.2007.04.007.

46. Burchmore RJS, Barrett MP. Life in vacuoles - nutrient acquisition by Leishmania amastigotes. Int J Parasitol. 2001;31:1311-20.

47. Real F, Mortara RA. The diverse and dynamic nature of Leishmania Parasitophorous vacuoles studied by multidimensional imaging. PLoS Negl Trop Dis. 2012;6(2):e1518. https://doi.org/10.1371/journal.pntd.0001518,

48. De Rycker M, Hallyburton I, Thomas J, Campbell L, Wyllie S, Joshi D, et al. Comparison of a high-throughput high-content intracellular Leishmania donovani assay with an axenic amastigote assay. Antimicrob Agents Chemother. 2013;57(7):2913-22. https://doi.org/10.1128/AAC.02398-12.

\section{Publisher's Note}

Springer Nature remains neutral with regard to jurisdictional claims in published maps and institutional affiliations.

Ready to submit your research? Choose BMC and benefit from:

- fast, convenient online submission

- thorough peer review by experienced researchers in your field

- rapid publication on acceptance

- support for research data, including large and complex data types

- gold Open Access which fosters wider collaboration and increased citations

- maximum visibility for your research: over $100 \mathrm{M}$ website views per year

At $\mathrm{BMC}$, research is always in progress.

Learn more biomedcentral.com/submissions 